\title{
Effect of Very-High-Flow Nasal Therapy on Airway Pressure and End-Expiratory Lung Impedance in Healthy Volunteers
}

\author{
Rachael L Parke RN PhD, Andreas Bloch MD, and Shay P McGuinness MB ChB
}

\begin{abstract}
BACKGROUND: Previous research has demonstrated a positive linear correlation between flow delivered and airway pressure generated by high-flow nasal therapy. Current practice is to use flows over a range of 30-60 L/min; however, it is technically possible to apply higher flows. In this study, airway pressure measurements and electrical impedance tomography were used to assess the relationship between flows of up to $100 \mathrm{~L} / \mathrm{min}$ and changes in lung physiology. METHODS: Fifteen healthy volunteers were enrolled into this study. A high-flow nasal system capable of delivering a flow of $100 \mathrm{~L} / \mathrm{min}$ was purpose-built using 2 Optiflow systems. Airway pressure was measured via the nasopharynx, and cumulative changes in end-expiratory lung impedance were recorded using the PulmoVista 500 system at gas flows of $30-100 \mathrm{~L} / \mathrm{min}$ in increments of $10 \mathrm{~L} / \mathrm{min}$. RESULTS: The mean age of study participants was 31 (range 22-44) y, the mean \pm SD height was $171.8 \pm 7.5 \mathrm{~cm}$, the mean \pm SD weight was $69.7 \pm 10 \mathrm{~kg}$, and $47 \%$ were males. Flows ranged from 30 to $100 \mathrm{~L} / \mathrm{min}$ with resulting mean \pm SD airway pressures of $2.7 \pm 0.7$ to $11.9 \pm 2.7 \mathrm{~cm} \mathrm{H}_{2} \mathrm{O}$. A cumulative and linear increase in end-expiratory lung impedance was observed with increasing flows, as well as a decrease in breathing frequency. CONCLUSIONS: Measured airway pressure and lung impedance increased linearly with increased gas flow. Observed airway pressures were in the range used clinically with face-mask noninvasive ventilation. Developments in delivery systems may result in this therapy being an acceptable alternative to face-mask noninvasive ventilation. Key words: oxygen therapy; high-flow nasal therapy; humidification; airway pressure; lung volume. [Respir Care 2015;60(10):1397-1403. (C) 2015 Daedalus Enterprises]
\end{abstract}

\section{Introduction}

Traditionally, a tightly sealed mask or an intubated airway has been used to deliver positive pressure to the lungs.

\footnotetext{
The authors are affiliated with the Cardiothoracic and Vascular Intensive Care Unit, Auckland City Hospital, Auckland, New Zealand. Drs Parke and McGuinness are also affiliated with the Australian and New Zealand Intensive Care Research Centre, Department of Epidemiology and Preventive Medicine, Monash University, Melbourne, Victoria, Australia and the Medical Research Institute of New Zealand, Wellington, New Zealand. Dr Bloch is also associated with the Department of Intensive Care Medicine, University Hospital (Inselspital) and University of Bern, Bern, Switzerland.
}

Research performed in the Cardiothoracic and Vascular Intensive Care Unit at Auckland City Hospital was supported in part by an unrestricted grant from Fisher \& Paykel Healthcare. Fisher \& Paykel Healthcare also supplied the consumables used in this study. This trial was registered prospectively at www.anzctr.org.au (ACTRN12613000047796). The authors have disclosed a relationship with Fisher \& Paykel Healthcare.
High-flow nasal therapy provides controlled oxygen concentrations and low levels of positive airway pressure via a nasal interface. ${ }^{1,2}$ It offers clinicians and patients an alternative mechanism for delivering low-level pressure without some of the complications and comfort issues associated with other methods. ${ }^{3,4}$ High-flow nasal therapy has been shown to improve oxygenation in diverse patient groups and is being used increasingly as an alternative to mechanical ventilatory support. ${ }^{5-7}$ These devices have also been shown to be efficacious when used in subjects with

\footnotetext{
Dr Parke presented a version of this report at the 26th Annual Congress of the European Society of Intensive Care Medicine, held October 5-9, 2013, in Paris, France.

Correspondence: Rachael L Parke RN PhD, Cardiothoracic and Vascular Intensive Care Unit, Auckland City Hospital, Private Bag 92024, Auckland 1142, New Zealand. E-mail: rparke@ adhb.govt.nz.
}

DOI: $10.4187 /$ respcare. 04028 
mild-to-moderate hypoxemic respiratory failure requiring respiratory support following extubation. ${ }^{8-10}$

Current practice is to use flows over a range of $30-50$ $\mathrm{L} / \mathrm{min},{ }^{11}$ resulting in low levels of positive airway pressure being delivered and helping to augment the functional residual capacity and therefore oxygenation in these patients. ${ }^{1,10-12}$ Research conducted previously has demonstrated that a positive linear correlation exists between the amount of flow delivered and the resulting airway pressure generated with conventional flows of $30-50 \mathrm{~L} / \mathrm{min} . .^{12,13}$

See the Related Editorial on Page 1522

Electrical impedance tomography is an evolving technology based on a noninvasive, radiation-free, and realtime approach that allows the user to gain information on global and regional lung ventilation. ${ }^{10}$ It continuously generates cross-sectional images of impedance distribution within a transverse slice of the thorax. ${ }^{14}$ With this imaging modality, it is possible to demonstrate changes in lung physiology in response to different airway pressures applied with mechanical ventilation or also with high-flow nasal therapy. ${ }^{14,15}$ Previous studies have demonstrated that changes in end-expiratory lung impedance ( $\Delta$ EELI) as measured by electrical impedance tomography have a strong linear correlation with changes in end-expiratory lung volume. ${ }^{10,14} \mathrm{Simi}-$ larly, tidal volume changes are correlated with tidal impedance variation. Thus, using electrical impedance tomography, the effects of high-flow nasal therapy can be assessed as changes in lung physiology rather than at a nasopharyngeal or oropharyngeal airway pressure level.

Because it is technically possible to apply higher flows than previously reported, we sought to describe the resulting changes in airway pressure and to see if the correlation remains linear at flows exceeding $50 \mathrm{~L} / \mathrm{min}$ in a group of healthy volunteers. One of the greatest concerns of clinicians is not knowing exactly how much pressure is generated by high-flow nasal therapy at different flows. ${ }^{16}$ Given the good clinical effect and low rate of adverse events seen in patients using high-flow nasal therapy, it seemed important to explore the effects of very high flows on healthy volunteers and the resulting effects before potentially expanding the use of highflow nasal therapy in the clinical setting.

\section{Methods}

Ethical approval was obtained from the Central Health and Disability Ethics Committee, New Zealand (12/CEN/79).

\section{QUICK LOOK}

\section{Current knowledge}

Heated-and-humidified high-flow oxygen has been shown to reduce ventilatory requirements by washing out the dead space of the upper airway and improving oxygenation by meeting patient demand with high oxygen concentrations and creating a low-level end-expiratory pressure. Gas delivered at body temperature and humidity is critical for patient comfort and tolerance of therapy.

\section{What this paper contributes to our knowledge}

In a group of normal subjects, high-flow nasal oxygen at $100 \mathrm{~L} / \mathrm{min}$ resulted in an increase in pharyngeal airway pressure of $1 \mathrm{~cm} \mathrm{H} \mathrm{H}_{2} \mathrm{O} / 10 \mathrm{~L} / \mathrm{min}$ of flow. As flow increased, breathing frequency decreased, and electrical impedance tomography demonstrated a small increase in end-expiratory lung volume. These findings cannot be directly extrapolated to patients with lung dysfunction and require investigation in clinical arenas.

The study was carried out at the Cardiothoracic and Vascular Intensive Care Unit of Auckland City Hospital in Auckland, New Zealand. Fifteen healthy volunteers were recruited.

\section{Study Subjects}

Subjects were recruited by word of mouth and information leaflets placed on noticeboards within the hospital. Informed consent was obtained from all subjects before any study procedures were undertaken.

Subjects were eligible for inclusion if they were $18 \mathrm{y}$ of age or older, written informed consent had been obtained, there were no known intrathoracic or upper-airway pathologies, the subject was not on any regular medication known to affect the cardiopulmonary system, and there were no known contraindications to the use of high-flow nasal therapy. The height, weight, ethnicity, and smoking and asthma history of each subject were recorded.

\section{High-Flow Nasal Therapy}

A specially constructed high-flow nasal system was created in collaboration with Fisher \& Paykel Healthcare (Auckland, New Zealand). To generate flows of optimally heated and humidified gas of up to $100 \mathrm{~L} / \mathrm{min}$, the system included 2 Fisher \& Paykel MR850 humidifiers delivering gas heated and humidified to $37^{\circ} \mathrm{C}\left(44 \mathrm{mg} \mathrm{H}_{2} \mathrm{O} / \mathrm{L}\right), 2$ RT202 circuits connected by a 22-mm Y-piece, and an 


\section{EFFect of Very-High-Flow Nasal Therapy}

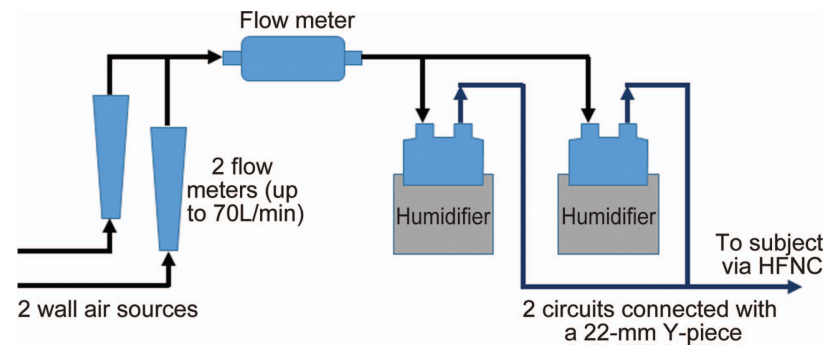

Fig. 1. Study schematic. HFNC = high-flow nasal cannula.

appropriately-sized nasal interface. A Mass Flowmeter 4040 (TSI, Shoreview, Minnesota) was inserted into the system to accurately measure the combined flow from 2 standard flow meters connected to 2 wall air supplies (Fig. 1). No supplemental oxygen was added to the gas flow.

\section{Airway Pressure Measurement}

Using a previously described technique, ${ }^{1}$ a 10 French catheter was inserted into the nasopharynx via the nose. Sterile surgical lubricant was used for insertion, and local topical anesthetic spray was offered to subjects if requested. Following positioning of the tube, end-tidal $\mathrm{CO}_{2}$ monitoring and visual inspection were used to confirm placement. Hypopharyngeal pressure was measured using a precision pressure transducer (PPT-0001 DWWW2VA-B, Honeywell, Morristown, New Jersey) with a laptop computer interface. Measurements at each flow were recorded during $1 \mathrm{~min}$ of breathing.

Following an initial baseline measurement recording with zero flow, high-flow nasal therapy was initiated at 30 $\mathrm{L} / \mathrm{min}$, and measurements were carried out in $10-\mathrm{L}$ increments up to a maximum of $100 \mathrm{~L} / \mathrm{min}$. A washout period of 5 min was included after each increase in flow before measurements were undertaken. Subjects were asked to breathe with their mouths closed but were advised that withdrawal from further measurements was permitted at any stage of the study. All subjects complied with the requirement to breathe with their mouths closed for the entire study period.

\section{Electrical Impedance Tomography Measurement}

All study personnel underwent training in the use of the PulmoVista 500 system (Dräger, Lübeck, Germany) before study startup. Subjects were placed in a semirecumbent position on a bed.

Before measurements were obtained with the PulmoVista 500, an automatic device check was performed following the manufacturer's recommendations. Next, an appropriately sized circumferential 16-electrode belt was fitted snuggly around the torso between the fourth and sixth intercostal spaces. The subject was prepared before application, ensuring that the skin was clean, dry, and free of moisture and excess hair. When necessary, electrode gel was applied to ensure adequate contact with the skin. The belt was fitted to ensure that the electrodes were equidistant from the sternum and that the center of the belt was against the subject's spine. A reference electrode was applied to the anterior abdomen. Once connected, the PulmoVista 500 system was calibrated, and the signal quality was checked to assess impedance of specific electrodes.

All electrical impedance measurements were taken at each gas flow during $1 \mathrm{~min}$ of steady breathing simultaneously with airway pressure measurement. All study procedures took $\sim 60 \mathrm{~min}$ in total, and the belt and nasopharyngeal catheter were removed at the end of the period.

\section{Monitoring}

All subjects had continuous peripheral oxygen saturation and heart rate monitoring in situ throughout the study period. A relevant medical history was recorded before beginning the study.

\section{Statistical Analysis}

Mean nasopharyngeal airway pressure was calculated by averaging the pressure from the peak of inspiration of the first breath to the peak of inspiration of the last breath during the 1-min recording. For every electrical impedance tomography image at each flow, the corresponding $\Delta$ EELI was calculated. The sequence of images during the 1-min recording at each flow was used to calculate the mean EELI. All measurements were stored on a USB (universal serial bus) memory stick attached to the PulmoVista 500 system for data analysis. Screenshots were also stored and exported at each change in flow (Fig. 2).

Data from both the pressure transducer and electrical impedance tomography measurements were downloaded into Excel (Microsoft, Redmond, Washington) spreadsheets for data analysis. Data were then extracted into GraphPad Prism 6.00 (GraphPad Software, San Diego, California) for analysis. To assess the relationship between flow and airway pressure, we used a linear regression model in which flow was the predictor and the mean pressure was the response. A $P$ value of $<.05$ was considered statistically significant. All data are presented as mean \pm SD unless stated otherwise and were tested for normality.

\section{Results}

Fifteen healthy volunteers were recruited and enrolled into this study. Subject characteristics are listed in Table 1. Only 2 subjects reported a history of asthma; neither used 


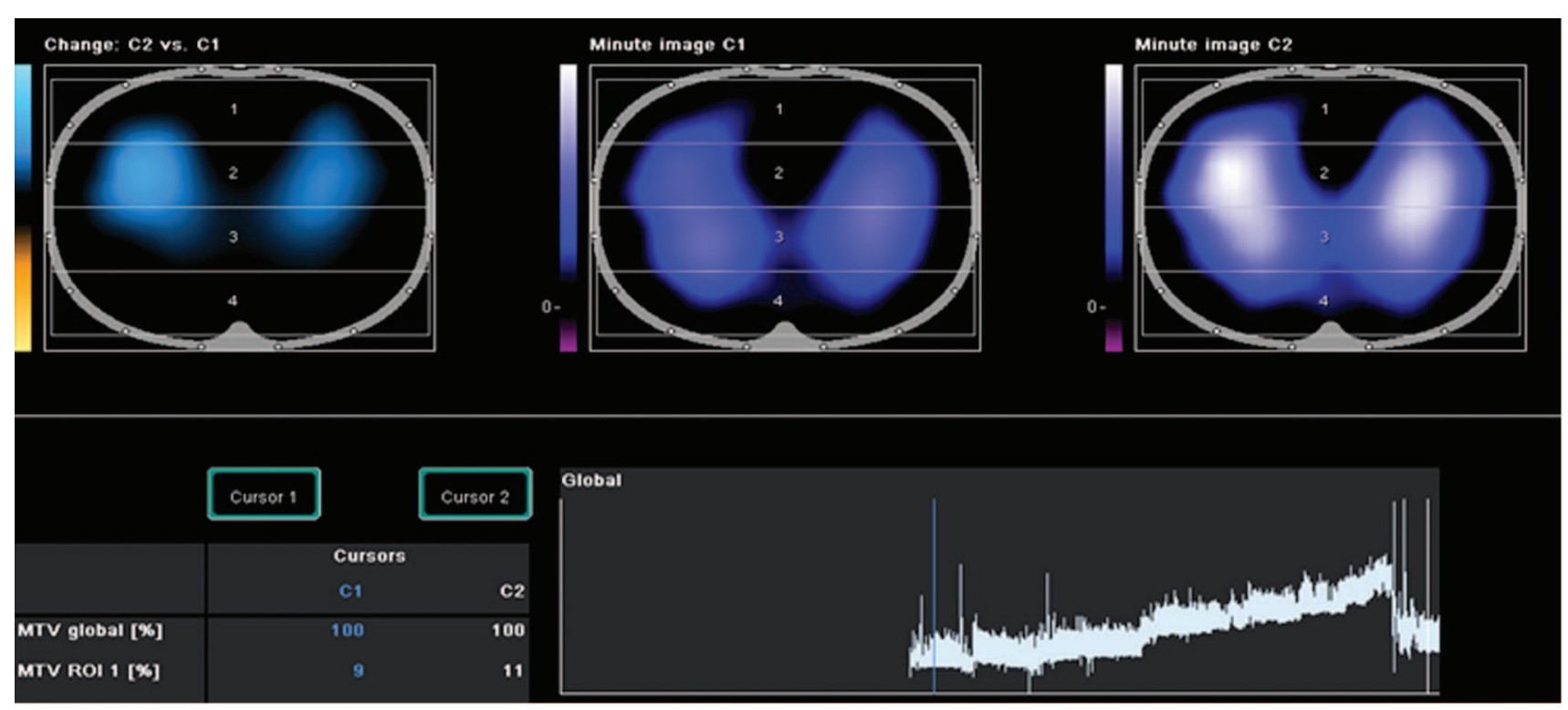

Fig. 2. Electrical impedance tomography images from a subject showing global end-expiratory lung impedance over the study period.

Table 1. Participant Characteristics

\begin{tabular}{lc}
\hline \hline \multicolumn{1}{c}{ Characteristic } & Values \\
\hline Females, $n(\%)$ & $8(53.3)$ \\
Males, $n(\%)$ & $7(46.7)$ \\
Age, mean y (range) & $31.9(22-44)$ \\
Weight, kg & \\
$\quad$ Mean \pm SD & $69.7 \pm 10.3$ \\
Range & $53-84$ \\
Height, cm & \\
Mean \pm SD & $171.8 \pm 7.5$ \\
Range & $164-185$ \\
BMI, kg/m ${ }^{2}$ & \\
Mean \pm SD & $23.5 \pm 2.6$ \\
Range & $20-29$ \\
Ethnicity, $n(\%)$ & $13(86.7)$ \\
European & $2(13.3)$ \\
Other & \\
\hline BMI = body mass index & \\
\hline
\end{tabular}

regular medications for this. Three were ex-smokers, and one was a current smoker.

A positive linear relationship existed between delivered gas flow and generated mean airway pressure (Fig. 3). On average, for every $10 \mathrm{~L} / \mathrm{min}$ increase in gas flow, the generated mean airway pressure increased by $1.16 \mathrm{~cm} \mathrm{H}_{2} \mathrm{O}$ $(P<.001)$. At the maximum flow of $100 \mathrm{~L} / \mathrm{min}$, the mean \pm SD generated airway pressure was $11.9 \pm 2.7 \mathrm{~cm}$ $\mathrm{H}_{2} \mathrm{O}$. There was significant intersubject variability seen, with airway pressures ranging from 7.2 to $16.2 \mathrm{~cm} \mathrm{H}_{2} \mathrm{O}$ measured at $100 \mathrm{~L} / \mathrm{min}$. As the gas flow was increased, there was an accompanying positive increase in the cumu-

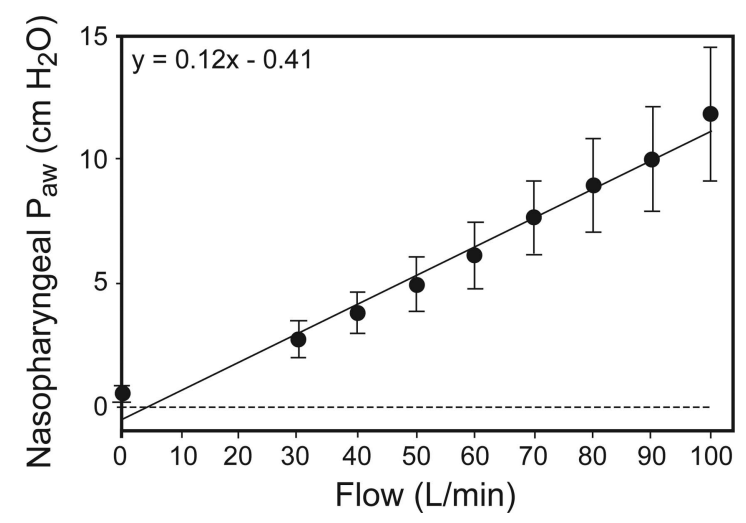

Fig. 3. Regression analysis of nasopharyngeal airway pressure $\left(\mathrm{P}_{\mathrm{aw}}\right)$ during high-flow nasal therapy. Data are shown as mean \pm SD.

lative $\Delta$ EELI (Fig. 4). Mean airway pressure and $\Delta$ EELI are provided for individual study participants in Table 2, and Figure 5 shows the relationship between $\Delta$ EELI, mean airway pressure, and mean breathing frequency.

Following initiation of nasal high flow, subjects' breathing frequencies were shown to drop significantly from baseline to a flow of $30 \mathrm{~L} / \mathrm{min}$ (median [interquartile range] of 14 [10-18] breaths/min versus 9 [7-10] breaths/min, $P<$.001) (Fig. 6). There was a further trend toward reduction as gas flow was gradually increased; however, this was not statistically significant. The median breathing frequency at $100 \mathrm{~L} / \mathrm{min}$ was 7 (5-8) breaths/min; however, it ranged from 3 to 23 breaths/min. There was no change in either heart rate or peripheral oxygen saturation measurements with changes in flows in these healthy and unstressed volunteers. 


\section{EFFECT OF Very-High-Flow Nasal Therapy}

\section{Discussion}

To our knowledge, this study is the first to investigate the physiological effects of high-flow nasal therapy with flows of up to $100 \mathrm{~L} / \mathrm{min}$. This study demonstrates that the linear increase in nasopharyngeal pressures that occurs using high-flow nasal therapy at the gas flows used in normal clinical practice $(30-60 \mathrm{~L} / \mathrm{min})$ continued when higher gas flows were used. Initiation of high-flow nasal therapy and increased flow also resulted in a substantial drop in breathing frequency and an increase in EELI and end-expiratory lung volume seen on electrical impedance tomography.

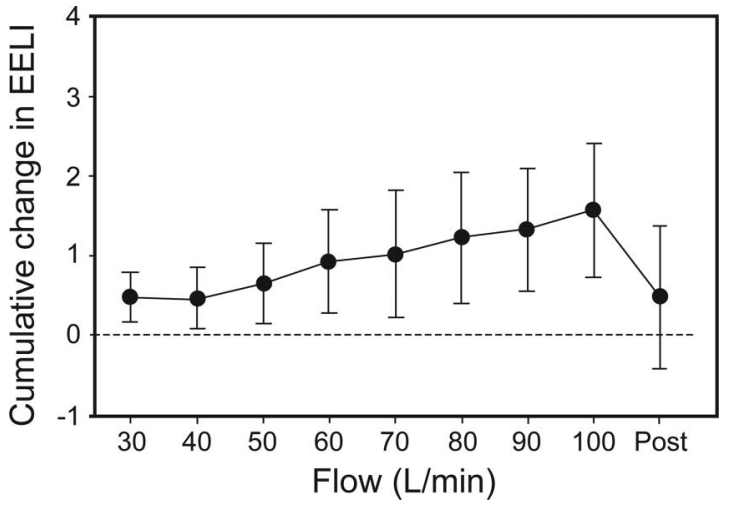

Fig. 4. Cumulative change in end-expiratory lung impedance (EELI) with high-flow nasal therapy. Data are shown as mean \pm SD.
This study corroborates earlier findings of a linear relationship between the delivered flow amount and the generated airway pressure with cannula flows of 30-50 $\mathrm{L} / \mathrm{min} .2,10,12,17$ The mean airway pressures produced in this study at these high flows (mean $8-12 \mathrm{~cm} \mathrm{H}_{2} \mathrm{O}$ ) are in the range normally associated with noninvasive ventilation using tightly-fitting face masks ${ }^{18}$ or even with conventional invasive ventilatory support, suggesting that there may be a further therapeutic role for the delivery of higher flows in patients who require more pressure support than can be

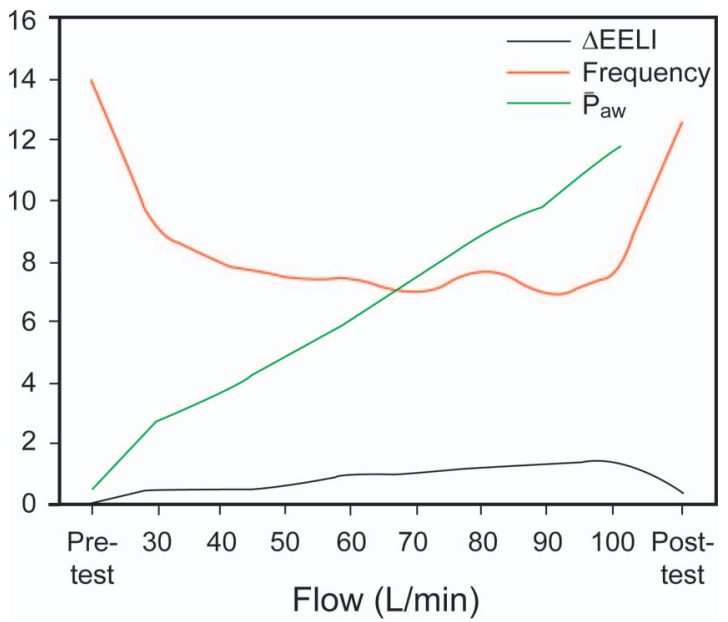

Fig. 5. Relationship between cumulative change in end-expiratory lung impedance $(\Delta \mathrm{EELI})$, mean breathing frequency, and mean nasopharyngeal airway pressure $\left(\overline{\mathrm{P}}_{\mathrm{aw}}\right)$.

Table 2. Airway Pressure and $\Delta$ EELI Data for Study Participants

\begin{tabular}{|c|c|c|c|c|c|c|c|c|c|c|c|c|c|c|c|}
\hline \multirow{2}{*}{ Parameter } & \multicolumn{15}{|c|}{ Study Participant } \\
\hline & 1 & 2 & 3 & 4 & 5 & 6 & 7 & 8 & 9 & 10 & 11 & 12 & 13 & 14 & 15 \\
\hline \multicolumn{16}{|c|}{ Mean airway pressure $\left(\mathrm{cm} \mathrm{H}_{2} \mathrm{O}\right)$} \\
\hline $0 \mathrm{~L} / \mathrm{min}$ & 0.5 & 0.5 & 0.5 & 0.9 & 0.5 & 0.5 & 0.5 & 0.5 & 0.4 & 0.7 & 0.5 & 0.5 & 0.5 & 0.5 & -0.7 \\
\hline $30 \mathrm{~L} / \mathrm{min}$ & 1.9 & 2.9 & 3.0 & 2.4 & 2.6 & 1.6 & 2.7 & 3.6 & 2.1 & 3.2 & 2.3 & 2.8 & 1.7 & 4.1 & 3.7 \\
\hline $40 \mathrm{~L} / \mathrm{min}$ & 2.6 & 4.0 & 4.5 & 2.8 & 3.4 & 3.6 & 3.3 & 4.5 & 3.1 & 4.5 & 3.1 & 3.7 & 3.3 & 5.4 & 5.1 \\
\hline $50 \mathrm{~L} / \mathrm{min}$ & 3.6 & 4.9 & 5.6 & 3.5 & 4.3 & 5.2 & 4.6 & 5.5 & 4.0 & 6.3 & 3.6 & 5.3 & 4.3 & 6.6 & 6.8 \\
\hline $60 \mathrm{~L} / \mathrm{min}$ & 5.3 & 6.1 & 7.4 & 4.2 & 5.7 & 5.7 & 5.4 & 6.5 & 4.3 & 8.1 & 4.8 & 6.5 & 5.3 & 8.6 & 7.9 \\
\hline $70 \mathrm{~L} / \mathrm{min}$ & 6.6 & 7.6 & 8.9 & 6.2 & 7.0 & 8.2 & 6.5 & 8.1 & 5.7 & 9.7 & 5.9 & 8.2 & 6.8 & 9.8 & 10.1 \\
\hline $80 \mathrm{~L} / \mathrm{min}$ & 7.6 & 8.5 & 10.6 & 7.2 & 7.9 & 9.0 & 7.6 & 10.0 & 6.0 & 11.5 & 6.8 & 10.7 & 8.3 & 11.9 & 11.4 \\
\hline $90 \mathrm{~L} / \mathrm{min}$ & 8.7 & 9.9 & 12.1 & 8.3 & 9.6 & 10.3 & 8.1 & 9.7 & 6.8 & 13.3 & 7.9 & 9.4 & 9.8 & 13.9 & 12.9 \\
\hline $100 \mathrm{~L} / \mathrm{min}$ & 10.6 & 12.1 & 14.0 & 9.8 & 11.1 & 10.7 & 10.5 & 16.2 & 7.2 & 15.6 & 8.4 & 9.9 & 12.2 & 14.5 & 15.4 \\
\hline \multicolumn{16}{|l|}{ Mean $\Delta$ EELI } \\
\hline $30 \mathrm{~L} / \mathrm{min}$ & 0.3 & 0.2 & 0.3 & 0.1 & 0.9 & 0.7 & 0.6 & 0.7 & 0.2 & 0.3 & 0.2 & 0.5 & 1.1 & 0.9 & 0.6 \\
\hline $40 \mathrm{~L} / \mathrm{min}$ & 0.5 & -0.1 & 0.2 & 0.0 & 0.8 & 0.7 & 0.5 & 0.9 & 0.1 & 0.0 & 0.3 & 0.3 & 1.0 & 1.0 & 0.8 \\
\hline $50 \mathrm{~L} / \mathrm{min}$ & 0.5 & -0.1 & 0.6 & 0.2 & 0.8 & 1.6 & 1.6 & 0.9 & 0.2 & 0.1 & 0.2 & 0.5 & 1.0 & 0.8 & 1.0 \\
\hline $60 \mathrm{~L} / \mathrm{min}$ & 1.5 & 0.0 & 0.9 & 0.5 & 0.9 & 1.7 & 1.9 & 1.5 & 0.2 & -0.2 & 0.5 & 0.7 & 1.3 & 1.3 & 1.3 \\
\hline $70 \mathrm{~L} / \mathrm{min}$ & 1.8 & 0.0 & 1.1 & 0.6 & 0.9 & 1.8 & 2.6 & 1.5 & 0.3 & -0.5 & 0.7 & 1.1 & 1.6 & 0.6 & 1.5 \\
\hline $80 \mathrm{~L} / \mathrm{min}$ & 2.2 & 0.2 & 1.3 & 1.1 & 1.0 & 1.8 & 2.9 & 1.6 & 0.3 & -0.4 & 0.8 & 1.3 & 1.6 & 1.2 & 1.6 \\
\hline $90 \mathrm{~L} / \mathrm{min}$ & 2.5 & 0.6 & 1.4 & 1.4 & 0.7 & 1.9 & 2.7 & 1.5 & 0.3 & -0.2 & 1.6 & 1.3 & 1.6 & 1.1 & 1.8 \\
\hline $100 \mathrm{~L} / \mathrm{min}$ & 3.0 & 0.7 & 1.6 & 1.4 & 1.1 & 1.9 & 2.8 & 1.6 & 0.5 & 0.2 & 0.7 & 2.3 & 2.0 & 1.7 & 2.1 \\
\hline
\end{tabular}

$\Delta \mathrm{EELI}=$ change in end-expiratory lung impedance 


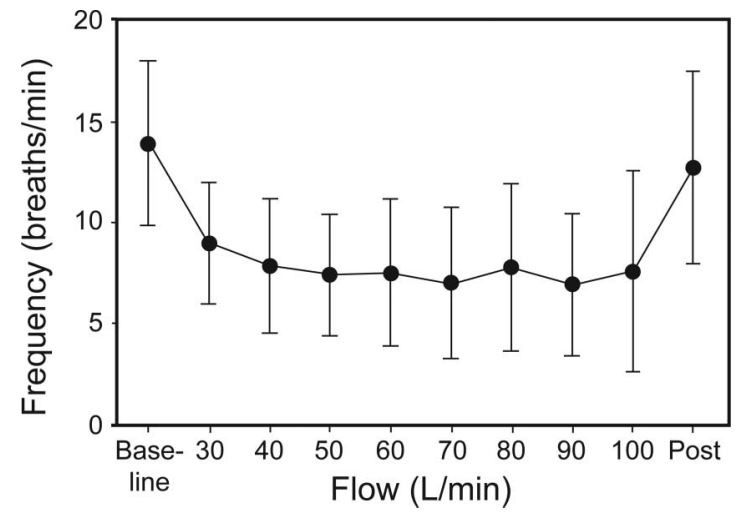

Fig. 6. Changes in breathing frequency with high-flow nasal therapy. Data are shown as mean \pm SD.

provided at conventional high-flow nasal therapy gas flows. Currently, owing to constraints placed by commercially available systems, clinicians are not able to deliver flows of $>60 \mathrm{~L} / \mathrm{min}$. As has been demonstrated previously $\mathrm{y}^{1,12,13}$ and as is evident from subject-level data (see Table 2), there is significant heterogeneity in the physiological variables measured between subjects, although there is a consistent increase in pressures with increased flow. It is likely that this variation is due to normal differences in upper-airway anatomy seen between subjects.

Several possible mechanisms have been proposed for the beneficial clinical effects of high-flow nasal therapy, including the provision of humidification, application of a positive airway pressure, and washout of the nasopharynx, resulting in a decrease in physiological dead space. ${ }^{19-21}$ One of the interesting findings of this study was that there was a consistent drop, between subjects, in breathing frequency on initiation of high-flow nasal therapy that plateaued at flows of $50 \mathrm{~L} / \mathrm{min}$. We hypothesize that this decrease in breathing frequency is due primarily to a reduction in physiological dead space, and the plateau effect seen is consistent with this because the expected benefits of nasopharyngeal washout may reach a ceiling at the flow that provides for no rebreathing of dead space gas. An alternative or additional explanation might be the washout of $\mathrm{CO}_{2}$ with the use of the applied fresh gas flows, such as seen in transtracheal gas insufflation in patients with ARDS.

Use of electrical impedance tomography and cumulative $\Delta$ EELI have only recently been employed to demonstrate changes in lung dynamics in non-mechanically ventilated subjects. ${ }^{10}$ We believe that the increase in EELI demonstrated represents an increase in functional residual capacity and possibly an increase in tidal volume. ${ }^{10}$ Further work assessing the effects of high-flow nasal therapy on pulmonary dynamics is desirable, recognizing that traditional methods used for measuring lung mechanics are difficult or impossible to use in the context of an open high-flow therapy such as high-flow nasal therapy.
Although our study enrolled a relatively small sample size, we found significant and consistent changes in airway pressure and end-expiratory lung volume measurements as flow was increased. While designing the study, concern was raised as to the tolerability of flows of up to $100 \mathrm{~L} / \mathrm{min}$. One ongoing issue with high-flow nasal therapy systems is the noise and feeling of increased pressure generated as flows increase. When enrolling subjects and undertaking study procedures, all subjects were informed that they could signal to the investigators at any time that they felt uncomfortable, and flows would be decreased or stopped. Interestingly, none of the subjects withdrew, all completed study procedures, and all tolerated the higher flows well. In fact, subjectively, all appeared to be comfortable at all flow levels while reading and playing games on tablets and phones, and 2 subjects even fell asleep. Although not measured objectively, the noise generated from this system was loud and may not be tolerated in the clinical environment by patients or staff on a daily basis. If manufacturers are to attempt to increase the flows generated by commercially available systems, some thought and effort would be required to address this issue.

\section{Limitations of This Study}

This study enrolled a small number of young healthy volunteers with normal body mass indexes and no comorbidities. Therefore, it is not known how these results may relate to a patient cohort or those with body mass indexes outside of a healthy range. It is also uncertain how they would relate to smokers or patients with existing lung pathologies.

It is also not entirely understood how $\triangle$ EELI exactly correlates to lung volumes. Even though the higher flows seem to correspond to higher airway pressures, we do not know the clinical effect on impaired oxygenation with higher flows. The effect on ventilation will need further attention regarding the amount and especially the mechanism; so far, we can only propose a hypothesis. Electrical impedance tomography has recently enjoyed renewed interest due to technological advances that make it easier to use at the bedside. Although it has limited proven efficacy in a clinical role, the finding of an increased EELI with increasing flow/pressure in this study is consistent with the physiological rationale of increased functional residual capacity. ${ }^{10}$ Our findings suggest that high-flow nasal therapy may be of benefit in patient groups currently managed with conventional noninvasive ventilation; however, further studies are required in different subject populations to evaluate any clinical benefits and potential adverse effects of these very high flows. Further evaluation of this technique is warranted, but until this occurs, clinical use should be restricted to clinical trials.

Finally, as this was a study of healthy volunteers, no outcome data were collected. However, we felt this was an 


\section{EFFECT OF Very-High-Flow Nasal Therapy}

important step to determine the effects of such high flows in healthy subjects rather than a patient cohort.

\section{Conclusions}

When using high-flow nasal therapy with gas flows significantly higher than currently used in clinical practice, we demonstrated that clinically important positive airway pressures were generated, with an associated decrease in breathing frequency. In addition, electrical impedance tomography strongly suggested an increase in end-expiratory lung volumes, indicating an increase in functional residual capacity with these higher gas flows.

\section{ACKNOWLEDGMENTS}

We thank Dr Callum Spence (Fisher \& Paykel Healthcare) for help in designing the high-flow nasal system used in this study.

\section{REFERENCES}

1. Parke R, McGuinness S, Eccleston M. Nasal high-flow therapy delivers low level positive airway pressure. Br J Anaesth 2009;103(6): 886-890.

2. Ritchie JE, Williams AB, Gerard C, Hockey H. Evaluation of a humidified nasal high-flow oxygen system, using oxygraphy, capnography and measurement of upper airway pressures. Anaesth Intensive Care 2011;39(6):1103-1110.

3. Hill NS. Complications of noninvasive positive pressure ventilation. Respir Care 1997;42(4):432-442.

4. Evans T. International consensus conference in intensive care medicine: non-invasive positive pressure ventilation in acute respiratory failure. Intensive Care Med 2001;27(1):166-178.

5. Sztrymf B, Messika J, Mayot T, Lenglet H, Dreyfuss D, Ricard JD. Impact of high-flow nasal cannula oxygen therapy on intensive care unit patients with acute respiratory failure: a prospective observational study. J Crit Care 2011;27(3):324.e9-324.13.

6. Roca O, Riera J, Torres F, Masclans J. High-flow oxygen therapy in acute respiratory failure. Respir Care 2010;55(4):408-413.

7. Rello J, Pérez M, Roca O, Poulakou G, Souto J, Laborda C, et al. High-flow nasal therapy in adults with severe acute respiratory infection: a cohort study in patients with 2009 influenza A/H1N1v. J Crit Care 2012;27(5):434-439.
8. Parke R, McGuinness S. An observational study of cardiac intensive care patients receiving nasal high flow therapy. Aust Crit Care 2010; 23(1):35

9. Parke RL, McGuinness SP, Eccleston ML. A preliminary randomized controlled trial to assess effectiveness of nasal high-flow oxygen in intensive care patients. Respir Care 2011;56(3):265-270.

10. Corley A, Caruana LR, Barnett AG, Tronstad O, Fraser JF. Oxygen delivery through high-flow nasal cannulae increase end-expiratory lung volume and reduce respiratory rate in post-cardiac surgical patients. Br J Anaesth 2011;107(6):998-1004.

11. Parke RL, Eastwood GM, McGuinness SP, George Institute for Global Health, Australian and New Zealand Intensive Care Society Clinical Trials Group. Oxygen therapy in non-intubated adult intensive care patients: a point prevalence study. Crit Care Resusc 2013;15(4):287293.

12. Parke RL, Eccleston ML, McGuinness SP. The effects of flow on airway pressure during nasal high-flow oxygen therapy. Respir Care 2011;56(8):1151-1155.

13. Parke RL, McGuinness SP. Pressures delivered by nasal high flow therapy during all phases of the respiratory cycle. Respir Care 2013; 58(10): 1621-1624.

14. Hinz J, Hahn G, Neumann P, Sydow M, Mohrenweiser P, Hellige G, Burchardi $\mathrm{H}$. End-expiratory lung impedance change enables bedside monitoring of end-expiratory lung volume change. Intensive Care Med 2003;29(1):37-43.

15. Leonhardt S, Lachmann B. Electrical impedance tomography: the holy grail of ventilation and perfusion monitoring? Intensive Care Med 2012;38(12):1917-1929.

16. Wettstein RB. A fresh look at the physiologic effects of high-flow nasal cannulae and the role they play in patient care. Respir Care 2013;58(4):715-716.

17. Groves N, Tobin A. High flow nasal oxygen generates positive airway pressure in adult volunteers. Aust Crit Care 2007;20(4):126131.

18. Parke RL, McGuinness S. A descriptive study of airway pressures generated by two methods of non-invasive respiratory support used in cardiac surgical patients. Am J Respir Crit Care Med 2011;183: A3184.

19. Masclans JR, Roca O. High-flow oxygen therapy in acute respiratory failure. Clin Pulm Med 2012;19(3):127-130.

20. Ward JJ. High-flow oxygen administration by nasal cannula for adult and perinatal patients. Respir Care 2013;58(1):98-122.

21. Lee JH, Rehder KJ, Williford L, Cheifetz IM, Turner DA. Use of high flow nasal cannula in critically ill infants, children, and adults: a critical review of the literature. Intensive Care Med 2013;39(2):247-257

This article is approved for Continuing Respiratory Care Education credit. For information and to obtain your CRCE

(free to AARC members) visit

www.rcjournal.com

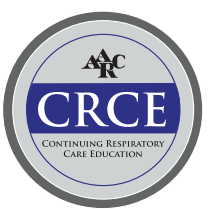

